\title{
Risks, Associated with LISP Projects
}

\section{Marina Tsurkan ${ }^{1, *}$ David Mamagulashvili ${ }^{2}$ Tatyana Uryadova ${ }^{3}$ Alexey Artemiev ${ }^{4}$}

\author{
${ }^{1}$ Department of Public Administration, Tver State University, Tver 170100, Russia \\ ${ }^{2}$ Department of Enterprise Economics and Management, Tver State University, Tver 170100, Russia \\ ${ }^{3}$ Department of Economic Analysis and Audit, Stavropol State Agrarian University, Stavropol 355017, Russia \\ ${ }^{4}$ Department of Geodesy and Cadastre, Tver State Technical University, Tver 170026, Russia \\ *Corresponding author. Email:080783@list.ru
}

\begin{abstract}
The paper discusses the risks, associated with participatory budgeting projects. In this light, the author analyzes the most common pattern - local initiatives support programs. The author identifies both the LISP projects risks and their mitigation measures. The article gives more accurate definition of the term "project risk management". The paper systematizes the economic categories that form part of this notion. The author has defined phases and stages of LISP project lifecycle and the risks that may appear at each stage. The author has proposed some risk mitigation measures for LISP projects. The given measures can be employed by various stakeholders.
\end{abstract} Keywords: project risks, project management, local initiatives support program, control

\section{INTRODUCTION}

Risk management is one of the key research areas of project management However, there are differences between various project management areas in terms of studying. For example, risk management for public-private partnership projects is thoroughly studied by experts, while intersectoral interaction projects risk management remains almost intact. Participatory budgeting is a process of development and approval, and/or distribution of the municipal budget as part of the project implementation approach assisted by the commission, which consists of the local authorities' representatives and the public. [1].

In a scanty number of scientific works, related to the participatory budgeting projects risk management the most prominent are those of M.V. Kurakolov, M.A. Schevelev [2], in which the authors analyze the risks of projects, which are implemented in urban districts from the point of view of people, who inhabit them.

The aim of the paper is to identify participatory budgeting projects risks, as exemplified by the most common pattern - Local initiatives support program (hereinafter - LISP) and to develop risk control and mitigation measures, which can be further implemented by various stakeholders.

\section{STUDY METHODOLOGY}

The research is based on the following theories: theory of management, which takes into account the principles that are suitable for public management procedures, performed by regional and municipal authorities; unbalanced growth theory, which is addressed in terms of intraregional development; feedback theory in management.

The primary research method is the structural levels strategy, proposed by the Doctor of Science in Economics, professor L.A. Karaseva [3]. This strategy allows considering LISP project risks as economic system elements and indicators of public management economic level in regions of the Russian Federation.

\section{RESULTS AND DISCUSSION}

\subsection{The concept of "project risk management"}

The elements of the term "project risks management" have different meanings in Russian and foreign scientific works, however there is a common approach to interrelated notions that constitute this economic category.

Most etymologic approaches to the definition of the term "risk" are limited to its English variant, as well as to French and Italian roots. In particular, in Italian "rischio" is the synonym to "danger" and "threat".

I.T. Balabanov [4] and D.M. Mashkov [5] argue that the terms risk" and "threat" are identical.

In Greek terms, a language unit "ridsikon" corresponds to the definition of "cliff", from "ridsa", "cliff" [6].

While analyzing the term risk", V.S. Nikolaenko [6] points out that D.I. Filimonov [7], V.N. Burkov and D.A. Novikov [8], I.I. Mazur and V.D. Shapiro [9] believe that the term "risk" is identical to "uncertainty".

Moreover, D.I. Filimonov gives negative connotations to the term "risk", as the uncertainty appears due to the absence or lack of information [7].

At the same time V.S. Nikolaenko points out that "uncertainty" and "risk" are two absolutely different notions, giving the following reasons:

"The uncertainty takes place, when there is a lack of data or information. The risk is based on the previous periods data, depends on the experience of the employees, etc. 
The uncertainty is linked to the probability of stochastic events occurrence. Any risk is caused by risk-contributing factors, which can be identified.

The uncertainty emerges, when the events forecasts are subjective and are made relying on intuition only. The risk forecasts are mainly based on objective factors" [6].

M.V. Romanova argues that "uncertainty is the incomplete or inaccurate data on the project implementation conditions, including results and expenses incurred” [10].

The author believes that the uncertainty factors are terms and conditions that have been neglected at the project planning stage: the more uncertainties there are at the project planning stage, the more risks can appear at the project implementation stage.

A.T. Zub argues that in terms of project management the notion "risk" means " the probability of unfavorable event occurrence along with all possible consequences” [11].

P. Sanghera's point of view is absolutely different. This author argues that any risk is of a dual nature, therefore, a risk event should be treated not only as a threat, but also as a positive opportunity [12].

In this approach "project management system is a set of managerial, procedural, informational tools, aimed at maximizing positive and mitigation of negative consequences, resulting from risk events in order to achieve strategic project goals” [13].

Thus, a project risk is a possible, measurable in numbers opportunity of unfavorable events emergence and consequences, associated with them, which can cause unexpected project results, regarding quantitative, qualitative and time values.

At the same time, risks are inherent part of project expenses. In each project there are special funds that are meant to cover possible risks, they can't be used for any other purposes, until the risk event possibility has been excluded [14].

R.S Gubanov emphasizes that P.G. Grabovaya and S.N. Petrova support this idea. They believe that risks is the probability of getting less benefits, compared to the expected results and (or) the probability of losses [15].

According to the textbook, edited by M.L. Razu, the risk probability is the probability of losses, resulted from the risk event occurrence, i.e. the probability of unfavorable outcomes. In this case the probability means the possibility of obtaining a certain result [16].

Speaking about the concept of "risk", V.S. Nikolaenko states that notions "risk", "risk source" and "risk factor" are interrelated [6].

Under a risk source the author means the objects and (or) conditions, which can potentially trigger the events that may influence the goals and activities of the enterprises.

A risk factor is a set of circumstances that exerts a certain impact on a risk source, increasing or decreasing the probability of risk occurrence [6].

It is worth mentioning that we should distinguish between risk and uncertainty factors, as "the uncertainty implies that there are some factors that make the activity results random. It is impossible to predict to what extent these factors may influence the results.

The uncertainty factors are:
Incomplete knowledge - incomplete or inaccurate data on project parameters and circumstances, as well as on situations that require proper decision-making. The impossibility of proper consideration of all the data, even if the data is available. The possibility to predict project environment behavior.

Random factors are the factors that are impossible to predict, even if we use probability estimates.

Subjective counterwork factors are the factors that emerge, when we speak about the cooperation of partners, whose interest don't coincide or contradict each other" [10].

A: I. Balashov, E.M. Rogova, M.V. Tikhonova, E.A. Tkachenko specify factors that stipulate the inevitability of risk emergence [17].

The authors distinguish 2 main factors: environment uncertainty and tight project resource.

The environment uncertainty can be expressed by the following:

- $\quad$ incomplete and unreliable information;

- a limited ability of managers to perceive and process information;

- $\quad$ accidental emergence of unfavorable events as a result of managerial activity;

- counterwork of competitors and contactors.

Tight project resources: physical; financial; labor and time ones [18].

Thus, project risks management is a system, which helps us to identify the risks at various project stages, to assess the severity of these risks (as well as the possibility of their emergence), to develop risk mitigation measures. To enable proper system functioning we should take into account riskcontributing factors and their sources along with uncertainty factors.

Let's dwell on public management risks, which are generally common for intersectoral interaction projects and participatory projects in particular.

Yu.A. Tikhomirova defines the public management risks as "a probable improper deviation from legal patterns and laws" [19].

According to the point of view of M. A. Lapina, mentioned by A.V. Tschegolev in his thesis [20], the public management risks are divided into two main groups: public legal risks and civil legal risks. The public legal risks are related to the wrong adoption and interpretation of laws and regulations. This group also includes executive legal risks, associated with errors during law enforcement and wrong interpretation of the current legislation. The civil legal risks depend on the society attitude towards current legal framework and its application [21].

The presented approach describes only general features, when we speak about the projects, implemented by public management structures, we should also consider specific project risks. They will be analyzed in terms of project budgeting below. 
- The submitted documents have been compiled

\subsection{The LISP projects: risks, associated with project stages implementation}

The LISP projects risks can be identified during different project lifecycle phases, and each phase can be subdivided into stages.

During the phase "Project planning and launching", at the stage Preliminary survey / discussion (identifying the issues of top-priority, possible contribution of the municipal unit population to the project that is to be implemented within the area, which these people inhabit) can emerge the following common risks:

- preliminary survey or discussion haven't been conducted;

- The representative share of the municipal unit population hasn't participated in the process, so the participants have failed to identify the issue of the top priority;

- . The representative share of the municipal unit population hasn't participated in the process. As a result, the agreed amount of funds that has to be contributed to the project is unacceptable for most residents of the municipal unit;

At the stage "The meeting of the residents of municipal unit, where the project is to be implemented", the following risks can occur:

- The residents' meeting hasn't taken place ;

- The residents are not eager to participate in the LISP. The representative share of the municipal unit population hasn't participated in the meeting, so the participants have failed to identify the issue of the top priority;

- The representative share of the municipal unit population hasn't participated in the meeting. As a result, the agreed amount of funds that has to be contributed to the project is unacceptable for most residents of the municipal unit;

- The object, chosen by municipal unit population can't participate in the LISP: it is not a public property, is not within the FL № 131, is beyond the regional LISP;

- There were no shooting and video recording of the meeting;

- There are errors in tender application documents or these documents haven't been compiled;

- The project initiative group hasn't been appointed; there are no volunteers;

- The project initiative group hasn't been appointed; there are too many volunteers;

- The meeting results haven't been published in the mass media.

According to the authors' point of view, the stage "Applying for the project to be included into the LISP by tender” implies the following risks: improperly. They don't meet the requirements of the approved application or protocol forms;

- The project names in the submitted documents don't coincide (i.e. in cost estimates, application, protocol);

- The submission deadline has been missed.

At the stage" Tender for the projects to be included in the LISP" there is a risk that the project will fail the tender.

For instance, in Tver region the LISP winning projects are selected in two stages: primary and supplementary selection procedures (distribution of regional budget funds, saved by the tender).

The stage «Execution of the agreement between the executive body that is responsible for regional projects implementation and the municipal unit that has won the tender" bears a risk that this agreement won't be signed, and a LISP project won't be implemented. The given possibility is the example of a project risk.

The project implementation phase begins with the stage "The announcement of municipal contract tender and signing this contract with the winner",

The three main risks of this stage are:

- There are errors in tender application;

- The deadlines for tender application submission haven't been met;

- The tender hasn't taken place due to the absence of tender participants.

At the stage "Submission of data on project implementation progress to the regional administrator within the time limits, established by a particular region of the Russian Federation" there is a risk that the data on project implementation progress and municipal contracts execution won't be provided to the regional Ministry of Finance in time.

The project co-financing on the part of the population of municipal unit, in which the project is to be implemented, may imply the following risks:

- The population doesn't want to provide financial support for the project;

- The co-financing on the part of the population is not sufficient;

- The funds have been collected, but haven't been transferred to the account of the municipal unit.

Risks of the phase "Project works performance":

- The deadlines have been failed;

- the municipal unit population is dissatisfied with the quality of the works performed;

- unfavorable weather conditions or other objective causes make it impossible to meet the deadlines;

- the works haven't been performed on schedule for unknown reasons.

Project completion phase can be divided into 4 stages

Project opening ceremony implies four risks:

- The population representatives haven't attended the event; 
- To supervise the process of the agreement execution with the tender winners (to check, if all the attachments are available);

- To check the reports on execution of municipal contracts, which are to be submitted to the Ministry of Finance in Tver region;

- To ensure that both population and legal entities have participated in the process of funds raising, to set cofinancing;

- To control work performance at sites (to involve construction experts from public bodies, so that they can check the quality of works performed);

- To check the documents that confirm payments, to ensure that all the necessary payments have been made;

- To check the reports on projects completion, which are to be submitted to the Ministry of Finance in Tver region;

- To check, if the photos of the finished object are present (the angles should be the same as in photos before project implementation started, there also should be photos of purchased equipment and special vehicles);

- To set the opening ceremony date for the LISP project object;

- To ensure that photos from the opening ceremony are present;

- To ensure that the photos of the finished object have been submitted to the Ministry of Finance in Tver region;

- To check the reports on grants use.

Some municipal control functions are also carried out by the regional Ministry of Finance, in particular:

- To check, if fault reports and all other documents necessary for proper cost estimates have been properly compiled by the units, (excluding equipment and special vehicles purchasing), (to involve construction experts from public bodies, so that they can eliminate technical and construction errors);

- To ensure that all the documents necessary for proper cost estimates compilation have been submitted and to check them in pricing regional center (excluding equipment and special vehicles purchasing);

- To track the amendments made to the municipal unit budget (all the sources, excluding local budget, project implementation expenses);

- To ensure that representatives of all local government bodies, interested in LISP implementation, are present at a LISP training;

- $\quad$ to inform the population, if the tender is lost;

- to supervise the process of the agreement execution with the regional Ministry of Finance;

- To control the compilation and distribution of tender applications (works terms, absence of advancing, support); - to check the contracts that have been celebrated with the tender winners, (if all the attachments are present); - to check the documents that confirm payments, to ensure that all the necessary payments have been made; 
However, some LISP project risks result from control measures, taken by regional authorities. For instance, the Ministry that is responsible for performing control functions in Tver region, checks the quality and the scope of works, performed in terms of LISP objects. If any defects or violations are found, the unit loses the right to a LISP grant. The initiative group controls the project throughout all the stages: from application submission to completion.

Participatory budgeting experts also identify specific risks, associated with project implementation in urban districts. The author believes that these risks emerge because the population of the mentioned municipal units is not eager to form local communities. The existence of other forms of participating projects that can provide a comfort urban environment is also a crucial factor for these risks.

\section{CONCLUSION}

The conducted research has driven us to the following conclusions:

- project risks management is a system, which helps us to identify the risks at various project stages, to assess the severity of these risks (as well as the possibility of their emergence), to develop risk mitigation measures. To enable proper system functioning we should take into account riskcontributing factors and their sources along with uncertainty factors;

- the uncertainty factors are terms and conditions that have been neglected at the project planning stage: the more uncertainties there are at the project planning stage, the more risks can appear at the project implementation stage;

- the LISP projects risks can be identified during different project lifecycle phases, and each phase can be subdivided into stages;

- Some risks can be mitigated by means of control measures, which are implemented by various stakeholders during the whole project lifecycle.

For further development of this topic we should assess the severity of the emerging risks, to develop risk mitigation measures.

The results of the present study can be employed by public authorities at the state and municipal levels. They are practically relevant for experts in economics and management.

\section{ACKNOWLEDGMENT}

Published with the support of Vladimir Potanin Grant Program.

\section{REFERENCES}

[1] M.V. Tsurkan, S.I. Sotskova, O.S. Aksinina, E.I. Sukhanova, S.Y Shirnaeva., M.A Lyubarskaya., O.N.
Tkacheva, A.G. Mokronosov. Influence of the Participatory Budgeting on the Infrastructural Development of the Territories in the Russian Federation. International Journal of Environmental and Science Education. 2016. T. 11. № 15. pp. 7684-7702.

[2] M.V. Kurakolov, M.A. Schevelev. Main features and risks, associated with initiative budgeting in urban districts. [Homepage] - Access mode: https://cyberleninka.ru/article/n/riski-i-osobennostirealizatsii-initsiativnogo-byudzhetirovaniya-vgorodskih-okrugah

[3] L.A. Karaseva. Use of structural levels strategy by economic system research. Bulletin of the Tver State University. Series: Economics and management. 2012, № 15. P. 25-33.

[4] I.T. Balabanov. Risk management, M.: Finance and statistics, 1996. - 192 p.

[5] D.M. Mashkov. Scientific approaches to risk management at industrial enterprises, Engineering Journal of Don, 2014, Vol.31, № 4-1, P. 65.

[6] V.S. Nikolaenko. The ideal risk management: practical guide, Tver: Tver branch of RANEPA; Tomsk, 2018. - 216 p.

[7] D.I. Filimonov. Personal security risks ranking for IT enterprises activities, Economics and Enterprise, 2017. - № 5-1 (82-1). - P. 682-685.

[8] V.N. Burkov, D.A. Novikov. Project management strategies. M., 1997, 188p.

[9] I.I Mazur, V.D. Shapiro. Project management, M. 2001, 502 p.

[10] M.V. Romanova. Project management: learning guide. M, 2010, $256 \mathrm{p}$.

[11] A.T. Zub. Project management: Theoretical and practical course for bachelor degree students. M. 2015, $422 \mathrm{p}$.

[12] P. Sanghera. PMP exam in depth, second edition: project management professional study guide for the PMP exam. - Course technology, a part of Cengage Learning, 2010. 592 p.

[13] Contract patterns, managerial motivation and incentives for projects / under general editorship of Doctor of science in engineering, professor Tsvetkov A.V., M, 2014, 126 P. 90

[14] Student workbook "Management trainings in such areas as health care, education and culture”, [Text]. Tver branch of RANEPA, 2016, 7 p. 
university under the government of the Russian Federation, M.: OT\& DO, 2014, 310 p. management strategy, Mining informational and analytical bulletin, 2008, № 7, P. 63-67.

[16] Project management. Basic principles of project management: a textbook / a team of authors; edited by professor M.L. Razu. - M, 2011. - 786 p.

[17] A.I. Balashov, E.M. Rogova, M.V. Tikhonova, E.A. Tkachenko. Project management: Theoretical and practical course for bachelor degree students, M. 2017, $383 \mathrm{p}$.

[18] Yu.A. Tikhomirova, M.A. Lapina. Public and private law risks: a joint monograph. Financial
[19] A.V. Tschegolev. Thesis for obtaining Ph.D. in economics. Integration of risk management tools into the public management system. Branch 08.00.05 Economics and national economy management). Access mode: https://swsu.ru/upload/iblock/da0/shchegolevav_dissert atsiya.pdf. (last accessed: 22.10.2019).

[20] M.A. Lapina. Risk management: theoretical and legal aspects, State and Law. 2015. № 2. P. 35-44. 